\title{
NARRANDO EM COLABORAÇÃO: AS CONSTRUÇÕES DISCURSIVAS DE UMA PESSOA COM AFASIA
}

\author{
Lívia Miranda de Oliveira* \\ Universidade Federal de Sergipe \\ Aracaju, Sergipe, Brasil \\ Liliana Cabral Bastos ${ }^{* *}$ \\ Pontifícia Universidade Católica do Rio de Janeiro \\ Rio de Janeiro, Rio de Janeiro, Brasil
}

\begin{abstract}
Resumo: Inserindo-se no quadro teórico-metodológico da Análise de Narrativa (RIESSMAN, 1993; 2008; BASTOS, 2005, 2008), este estudo vale-se de estudos canônicos (LABOV; WALETZKY, 1967; LABOV, 1972) e interacionais (NORRICK, 2000; GOODWIN, 1986) para investigar a construção colaborativa da narrativa e as construções discursivas de uma pessoa com afasia. Elegendo a proposta das dimensões da narrativa de Ochs e Capps (2001) como categoria analítica, pudemos observar um alto envolvimento das conarradoras na construção da narrativa, sobretudo em seu encaixe na atividade discursiva, bem como a emergência da linearidade também como um empreendimento que conta com a cooperação das conarradoras. Além disso, destacaramse as habilidosas escolhas retóricas da narradora (de recursos avaliativos) na construção da alta historiabilidade de sua narrativa, e seu alinhamento a uma postura moral positiva, determinada e constante.
\end{abstract}

Palavras-chave: Narrativa. Interação. Afasia.

1 INTRODUÇÃO

A afasia é uma perturbação nos processos de significação, em que há alterações linguísticas, com repercussões no funcionamento discursivo, sendo causada por lesão cerebral decorrente de acidente vascular cerebral (AVC), traumatismo crânioencefálico (TCE), tumor, entre outras afecções neurológicas. Para além da lesão cerebral, um sujeito é afásico quando lhe faltam recursos de produção e interpretação para exercer a linguagem (COUDRY, 2008).

Levando em conta as limitações linguísticas de pessoas com afasia, deve-se considerar que algumas peculiaridades emergem nas trocas discursivas em que elas se envolvem. Pessoas com afasia, por exemplo, muitas vezes, não conseguem construir seus enunciados sozinhas ou, em outros momentos, constroem enunciados pouco inteligíveis, que frequentemente incitam reparos de interlocutores, que passam a ser

\footnotetext{
* Doutora em Estudos da Linguagem. Professora do Departamento de Fonoaudiologia, Centro de Ciências Biológicas e da Saúde da UFS.

${ }^{* *}$ Doutora em Letras. Professora do Departamento de Letras, Centro de Teologia e Ciências Humanas da PUC-Rio.
} 
mais colaborativos, muitas vezes, concedendo a essas pessoas um tempo maior para produzirem seus enunciados, em outras palavras, maximizando os turnos de fala do interlocutor afásico. Essa maximização de turnos presente em conversas de pessoas que apresentam afasia está claramente em contraste com a organização de conversas ordinárias e suas preferências por minimização de turno, (WILKINSON; BEEKE; MAXIM, 2007).

Se a afasia afeta certas estruturas e usos da língua, por sua vez, o sujeito afásico busca outros modos/ arranjos para significar/ associar, ou seja, produz processos alternativos de significação (COUDRY, 2008)' Assim considerando, pessoas com afasia frequentemente se veem frente à possibilidade de tentar produzir sentenças conforme padrões estruturais, estando sujeitas a incorrer em agramatismos (terminologia advinda da literatura afasiológica tradicional), ou de adequá-las às suas limitações, produzindo sentenças mais curtas. $\mathrm{O}$ fator decisivo para essa escolha pode ser considerado o contexto (e.g. informal ou formal) (HEECHEN; SCHEGLOFF, 2003).

Estudos seminais acerca das afasias (GOLDSTEIN, 1939, 1948; JACKSON, 1931) espraiam a visão de que o comportamento linguístico de pessoas com afasia pode ser visto, no mínimo em parte, como uma manifestação da adaptação aos efeitos da lesão subjacente, ao invés de simplesmente ser um reflexo direto dessa lesão. Nas palavras de Wilkinson et al. (2007), as estratégias utilizadas por essas pessoas para lidar com o déficit linguístico envolvem adaptação do uso de recursos linguísticos limitados de modo a lidar com as exigências de contribuição com a interação em curso.

Apostando nessa capacidade de pessoas com a afasia de lidar com (usar) a linguagem, o interesse deste artigo se volta para as construções discursivas dessas pessoas, ao invés de se voltar para os déficits por elas apresentados, deslocando, então, o foco da patologia (do déficit) para o indivíduo (e suas construções discursivas) que a apresenta. Eleger o discurso do aqui e agora como fenômeno de interesse, não é negligenciar os déficits e seus efeitos no uso da linguagem, mas sim voltar a atenção para aquilo que pessoas com afasia conseguem fazer com (e através de) a linguagem, ao invés focar naquilo que elas não conseguem fazer.

Em suma, embora este seja um estudo que envolve uma pessoa com afasia, sua meta não consiste em analisar os déficits linguísticos apresentados, mas, ao contrário, consiste em tentar entender como essa pessoa, juntamente com os outros participantes da interação, constrói sua história de AVC. O estudo aqui apresentado volta-se para categorias interacionais - narração (aqui entendida como a ação inter-acional de narrar), historiabilidade, encaixe, linearidade e postura moral (cf. OCHS; CAPPS, 2001) - com base nas quais observaremos como uma pessoa com afasia constrói interacionalmente sua narrativa, bem como se constrói como narradora.

Por meio do entrelace de perspectivas mais canônicas ${ }^{1}$ e estruturais com abordagens interacionais de estudo de narrativas, pretende-se contribuir para as pesquisas desenvolvidas na interface estudos da linguagem e estudos das afasias,

\footnotetext{
${ }^{1} \mathrm{Na}$ literatura da área dos estudos socioculturais e sociointeracionais de narrativa (MISHLER, 1999; OCHS; CAPPS, 2001; RIESSMAN, 1993; 2008, entre outros) se usa o termo 'canônico' em referência ao modelo laboviano.
} 
ocupando um lugar no território da Análise de Narrativa (cf. RIESSMAN, 1993; 2008). A partir desse lugar, então, esta pesquisa almeja agregar mais um modo de se olhar para narrativas de pessoas com afasia aos estudos que vêm sendo desenvolvidos nesse campo.

\section{ESTUDOS DA NARRATIVA: DO CÂNONE LABOVIANO À PERSPECTIVA INTERACIONAL}

Este estudo se alinha à concepção de narrativa como uma prática social, uma atividade histórica e culturalmente situada (BASTOS, 2004), e sustenta que, ao narrar, o narrador não apenas transmite seu sentido de self, mas também constrói relações com os outros e com o mundo que o cerca (BRUNER, 1990; BASTOS, 2005).

A análise aqui empreendida se faz a partir de uma abordagem híbrida, que conjuga estudos de natureza mais estrutural a estudos interacionais, bem como contribuições advindas de outras áreas das ciências sociais, notadamente da antropologia. Nesse sentido, a proposta de Ochs e Capps (2001) atende bem aos interesses dessa interdisciplinaridade e foi eleita para compor o arcabouço teórico das investigações deste artigo.

Para as autoras, a narrativa que iremos analisar consiste em uma narrativa pessoal, que, por sua vez, é definida como "uma forma de usar a linguagem ou outro sistema simbólico para costurar eventos da vida em uma ordem lógica e temporal, para desmistificá-los e estabelecer coerência, por meio da experiência passada, presente ou ainda não realizada" (OCHS; CAPPS, 2001, p. 2). Assim considerando, "contar histórias é um dos modos significativos dos indivíduos construírem e expressarem sentidos" (MISHLER, 1999, p. 67).

No cenário das interações sociais, como será possível observar na análise, o conteúdo e a direção que as narrativas assumem são, conforme Ochs e Capps (2001), contingências do input narrativo dos interlocutores, que fornecem, eliciam, criticam, refutam e esboçam inferências. Tal concepção traz consigo a visão de que as narrativas são coconstruídas pelos interlocutores, configurando-se como uma realização interacional, ao invés de uma produção de um único falante.

As autoras apresentam a proposta de que a estrutura da narrativa contém todos ou alguns dos seguintes componentes do discurso: descrição, cronologia, explicação e avaliação. Podemos traçar um paralelo desta proposta de estrutura narrativa com a proposta de Labov (1972), segundo a qual uma narrativa compreende elementos tais como orientação (quem participa, quando, do quê, onde?), ação complicadora (então, o que aconteceu?), avaliação (e daí? Qual a relevância disso?) e resolução (resultou em quê?). Nesse paralelo, tais elementos se aproximariam, respectivamente, de descrição (orientação), cronologia (ação complicadora), explicação e avaliação (avaliação). Além desses elementos, Ochs e Capps (2001) destacam que ações conversacionais, como por exemplo, perguntas, clarificações, desafios e especulações costumam penetrar narrativas conversacionais.

Ademais, conforme bem destacam as autoras, as narrativas são permeadas por avaliações morais e estéticas das ações, emoções, pensamentos, e condições mundanas. 
Para tanto, as narrativas lançam mão de valores e discursos de senso comum circulantes em uma cultura particular (RIESSMAN, 2008), de modo que "o uso de entendimentos culturais é inevitável" (MISHLER, 1999, p. 95). Cabe ressaltar que é por meio das avaliações que o narrador revela seu ponto de vista (cf. LABOV, 1972), que traz consigo valores culturais, já que se trata do ponto de vista de um indivíduo inserido em uma determinada cultura e por ela influenciado e informado.

Ochs e Capps (2001) consideram que, de todos os componentes pertencentes à estrutura de uma narrativa, o melhor candidato a distinguir a narrativa de outros fragmentos discursivos é a cronologia, uma vez que a ordenação sequencial de dois ou mais eventos é considerada a marca principal da narrativa. Esse critério definidor de narrativa foi inicialmente proposto por Labov e Waletzky (1967), que também entendem a narrativa como uma sequência de eventos passados ordenados temporalmente, e é adotado por alguns estudiosos de narrativa que conjugam aos estudos labovianos estudos interacionais e culturais sobre narrativa (e.g. BASTOS, 2008).

Dado o caráter interacional das narrativas, as autoras sugerem um exame das seguintes dimensões (de caráter interacional) na narrativa: narração, historiabilidade, encaixe, linearidade e postura moral. Com base nessas dimensões, as autoras analisam (i) como diferentes interlocutores estruturam a narração de uma história e (ii) como eventos cotidianos são estruturados através da narrativa. Tais aspectos também serão investigados neste artigo, por meio do uso desse mesmo instrumental analítico.

A gama de possibilidades de cada dimensão pode ser melhor visualizada no quadro abaixo, em que Ochs e Capps (2001) apresentam duas colunas que representam dois extremos de um continuum sobre o qual se estendem as dimensões.

\section{Quadro 1 - Dimensões da narrativa}

\begin{tabular}{|l|l|l|}
\hline Dimensões & \multicolumn{2}{|c|}{ Possibilidades } \\
\hline Narração & Um narrador ativo & Múltiplos conarradores ativos \\
\hline Historiabilidade & Alta & Baixa \\
\hline Encaixe & Isolada & Encaixada \\
\hline Linearidade & Ordem causal e temporal finalizada & Ordem causal e temporal em aberto \\
\hline Postura moral & Determinada, constante & Indeterminada, fluida \\
\hline
\end{tabular}

Fonte: Ochs; Capps, 2001, p. 20

Conforme sumarizado no quadro acima, a dimensão narração se refere ao número de pessoas envolvidas na narração e ao tipo de envolvimento dessas pessoas. $\mathrm{O}$ envolvimento relativamente baixo na conarração é característico de narrativas em que prevalece um narrador e os parceiros conversacionais sustentam o papel de interlocutores relativamente passivos, ao passo que o envolvimento relativamente alto caracteriza interações narrativas em que, embora uma pessoa possa ser identificada como narrador primário, importantes contribuições são realizadas por mais de um interlocutor. 
Para Goodwin (1986), o papel ativo exibido pelos interlocutores no curso da narração pode ser produto da atividade discursiva na qual eles estão engajados (por exemplo, uma conversa), ao invés de ser uma característica intrínseca. Assim sendo, contar uma história pessoal é uma atividade social e cultural que varia em amplitude e tipo de participação dos interlocutores, sendo os componentes da narrativa constituídos, ordenados e elucidados através da colaboração social (OCHS; SMITH; TAYLOR, 1988).

A dimensão historiabilidade está relacionada à razão de ser da narrativa (cf. LABOV, 1972). De acordo com Ochs e Capps (2001, p. 76), "a historiabilidade é uma dimensão narrativa que varia de um foco retórico sobre uma quebra de expectativa altamente reportável e suas notáveis consequências (alta historiabilidade) a relato de eventos relativamente ordinários (baixa historiabilidade)".

De acordo com Oliveira e Bastos (2002), a historiabilidade não se limita àquilo que, com base em nosso conhecimento de mundo, reconhecemos como extraordinário, podendo até mesmo estar relacionada à razão que levou o narrador a escolher determinado evento para ser tratado como extraordinário, consistindo, portanto, em um produto do processo interacional em que a narrativa acontece.

A esse respeito, Norrick (2000) argumenta que o conteúdo da história não necessita ser relevante ou interessante se os conarradores sustentarem um alto envolvimento na narração, sendo a historiabilidade uma questão de negociação.

Narrativas de experiência pessoal variam, também, em termos de seus encaixes no discurso circundante e na atividade social, sendo que "a extensão na qual uma narrativa pessoal é uma entidade por si só, separada do discurso precedente, corrente e subsequente, está relacionada à organização do turno, ao conteúdo temático e à estruturação retórica" (OCHS; CAPPS, 2001, p. 36). Narrativas relativamente isoladas podem, por exemplo, recontar uma experiência (i) em um ou mais turnos longos, ou (ii) cujo conteúdo temático não está relacionado com o tópico em curso ou o foco de atenção, ou, ainda, (iii) em um formato retórico distinto daquele do discurso circundante, ao passo que, narrativas de experiência pessoal relativamente encaixadas (i) não apresentam um formato de tomada de turno distinto (sendo contadas em turnos de extensões similares aos turnos que as precedem), (ii) são tematicamente relevantes a um tópico sob discussão ou a uma atividade em andamento, e (iii) seus formatos retóricos também assumem características do discurso circundante.

No que tange à dimensão linearidade da narrativa, Ochs e Capps (2001) colocam que, no curso da narração, pode haver quebra da linearidade, por exemplo, quando (i) a sequência temporal é interrompida, (ii) o enredo carece de coerência, (iii) o narrador realiza um flash back, (iv) o narrador sai do mundo da história e volta ao mundo real, de modo que suas construções com verbos no passado cedem lugar a construções com verbos no presente, e (v) ocorre repetição de enunciados e temas. Tais critérios de quebra de linearidade serão identificados e destacados na narrativa aqui analisada; todavia, como veremos, serão tratados como fatores que provocam um desvio do fluxo da narração, mas não como uma quebra.

No tratamento da dimensão postura moral, é importante ter em conta que com base em seus próprios valores, as diferentes culturas tratam seus membros como agentes 
morais e deles são esperadas atitudes adequadas às situações, aos papéis, aos relacionamentos, às instituições e à sociedade. As narrativas podem constituir um recurso comunicativo para a manutenção da moralidade, pois, através delas, determinam-se verdades morais e constroem-se posturas morais, informados por valores culturais.

Conforme Bastos (1999, p. 27), "o que é dito nas histórias de vida relaciona-se também com construções sociais mais amplas, pois elas contêm pressuposições sobre o que pode ser tomado como certo ou errado, sobre quais são as normas e sistemas de crenças nos diferentes grupos sociais". A autora coloca que, ao contarem histórias, "os narradores não apenas refletem, mas também atuam na manutenção e construção dos sistemas de valores que subjazem ao nosso comportamento social" (BASTOS, p. 2728). Em uma ação recíproca, portanto, as narrativas são formatadas (por) e formatam a realidade quando o narrador faz seu recorte singular da realidade, influenciado por uma matriz de princípios e valores.

Ochs e Capps (2001) defendem que a postura moral assumida pelos narradores e protagonistas (em relação aos eventos) é um aspecto central no estudo das narrativas, e que, enraizada na comunidade e na tradição, a postura moral é uma disposição acerca do que é bom ou valorável e de como alguém deve viver no mundo.

Enfim, o modelo analítico de Ochs e Capps faz-se muito útil para analisar narrativas mais ou menos convencionalmente estruturadas, ou mais ou menos internacionalmente construídas. Por essa razão, a proposta das autoras atende muito bem aos interesses deste estudo, de modo que elegemos as dimensões da narrativa por elas apresentadas como categorias analíticas das investigações realizadas.

\section{METODOLOGIA E CONTEXTUALIZAÇÃO DOS DADOS}

Este estudo assume uma postura qualitativa e interpretativista de análise dos dados e se insere no quadro teórico-metodológico da Análise de Narrativas (cf. RIESSMAN, 1993).

No que tange ao contexto de geração dos dados, podemos defini-lo como entrevista de grupo focal, que consiste em "uma técnica de pesquisa que coleta dados através de interação em grupo sobre um tópico determinado pelo pesquisador" (MORGAN, 2002, p. 141). Na condição de estudioso do método de entrevista de grupo focal, Morgan (2002) apresenta distintas configurações de arranjos interacionais desse tipo de grupo que vão desde abordagens mais estruturadas a abordagens menos estruturadas, como é o caso deste estudo. Estas últimas (i) visam entender o modo de pensar dos participantes; (ii) tratam os interesses dos participantes como dominantes; (iii) levantam questões, guiam a discussão; (iv) apresentam menor número de questões específicas, sendo as questões mais gerais; (v) defendem uma flexibilidade de alocação do tempo; (vi) estabelecem a presença de um moderador que facilita a interação e que explora novas direções; e (vii) favorecem interação entre os próprios participantes, que não se limitam a interagir apenas com o moderador. 
A partir de interações em um grupo focal conduzido de forma menos estruturada, foi possível constituir um corpus de interações face a face gravadas em vídeo e transcritas de acordo com as convenções propostas pelos analistas da conversa (cf. anexo A). Desse corpus, foi extraída a história de AVC contada por Carla, uma das participantes do grupo focal.

Carla é o pseudônimo da participante mais velha do grupo (55 anos) e com maior tempo de acometimento pelo AVC (10 anos). Assim como as outras participantes da pesquisa, Carla apresenta afasia em decorrência de um AVC, que deixou como sequela, além do comprometimento linguístico (que aqui não cabe ser detalhado), uma hemiparesia à direita. Ela era secretária executiva e, na época da pesquisa, estava aposentada por invalidez, divorciada e morava com sua mãe e seu filho adolescente.

Além de Carla, faziam parte do grupo focal duas pacientes do ambulatório de neurologia do hospital da Universidade Federal de Juiz de Fora, cujos pseudônimos eram Tereza e Laura. Após assinatura do Termo de Consentimento Livre e Esclarecido pelas três participantes, iniciaram-se os encontros para geração de dados que aconteceram semanalmente, às sextas-feiras, excetos feriados, no período de agosto a dezembro de 2007, em um laboratório do Instituo de Ciências Humanas da Universidade Federal de Juiz de Fora, e foram gravados em vídeo.

No primeiro encontro, as participantes, motivadas pela pesquisadora/moderadora (Lívia), conversaram sobre o AVC que as acometeu, sobre as sequelas por ele deixadas, entre elas, a afasia. Tópicos relacionados a AVCs, então, foram levantados para discussão pela pesquisadora/ moderadora, que, em um determinado momento da interação, conduziu as participantes a se engajarem na narração de suas histórias de AVC, das quais uma foi selecionada para ser analisada logo a seguir.

Para conduzir o empreendimento analítico a ser aqui apresentado, selecionamos, conforme já mencionado, as dimensões de Ochs \& Capps (2001) como categorias analíticas (narração, historiabilidade, encaixe, linearidade e postura moral) e delineamos cinco questões investigativas que serão paulatinamente apresentadas e respondidas ao longo da análise.

4 ANÁLISE

Em um primeiro momento, apresentaremos a narrativa de Carla completa, sem recortes, conforme nos sugere Riessman (1993), uma vez que nossa pretensão é uma análise interacional que captura nuances do turno a turno da narração, o que inclui tanto as falas do narrador primário como as falas dos conarradores. Em seguida, retomaremos as perguntas investigativas a fim de respondê-las com a análise.

História de Carla 
003

004

005

006

007

008

009

010

011

012

013

014

015

016

017

018

019

020

021

022

023

024

025

026

027

028

029

030

031

032

033

034

035

036

037

038

039

040

041

042

043

que foi- >ela já contou a dela, só pra elas verem

se foi igual $\downarrow<\quad)$

Carla: é:: é:: rosana, minha tia, foi me buscar, é:: no aniversário. é: : eu ... é: : vou é: : ... junto com ela. aí, na casa dela, eu: é:: retrato, eu é: : via é: quinze anos da filha dela. aí é: choveu. é: : tava

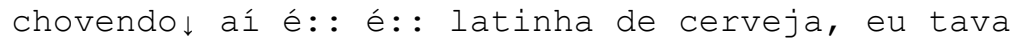
tomando, uma latinha de cerveja só. (lfaz um gesto com a mão esquerda de aproximação dos dedos indicador e polegar, sinalizando pouca quantidade)) aí é:: quer que eu é:: é::- a roupa dela tava no é::

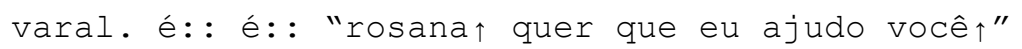
ajudei, né $\downarrow$ é: : roupa é:: no quarti::nho. ela entrou e eu entrei (.) na frente. é: "meu braço tá doendô" ((realiza um gesto com o braço esquerdo sinalizado

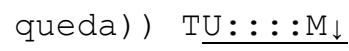

Lívia: igual ao dela.

Carla: é. tu:: : : : :

Lívia: foi súbito.=

Carla: = é. $=$

Lívia: = foi rápido.=

Carla: $=\dot{e} .=$

Lívia: = foi na hora. =

Carla: é: .

Lívia: aí você acordou- você desmaiou e acordou como?

Carla: é: : no hospital ((risos)).

Laura: e: : torta?

Lívia: >ela não lembrava,<

Carla: não. é: : em coma, é: : três- é: : (lfaz gesto com a mão esquerda sinalizando quatro)) quatro dias em coma.

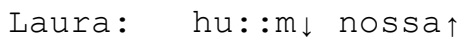

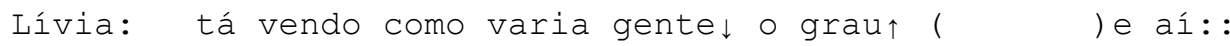
mas quando você voltou à consciência, o que você lembra? [ como você estava]

Carla: [ é:: nada.] num lembro de nada. (.) é:: [ é: : é: :

Laura: [ é:: mas avc é:: stress?

Carla: é: : fumava e bebia.

Laura: você? Eu fumava também $\downarrow$

Carla: hum $\downarrow$ ((sorri e franze a testa))

Carla: é:: aqui:: minha irmã é:: é: : é:: minha irmã, ligou pra minha mãe, é:: "carla desmaiou aqui"

Lívia: a é:: o seu caso. [ continua a contar,

Carla:

[é. é: : é: : desmaiou aqui. é: : é: :

OLIVEIRA, Lívia Miranda de; BASTOS, Liliana Cabral. Narrando em colaboração: as construções discursivas de uma pessoa com afasia. Linguagem em (Dis)curso - LemD, Tubarão, SC, v. 14, n. 2, p. 247-267, maio/ago. 2014. 


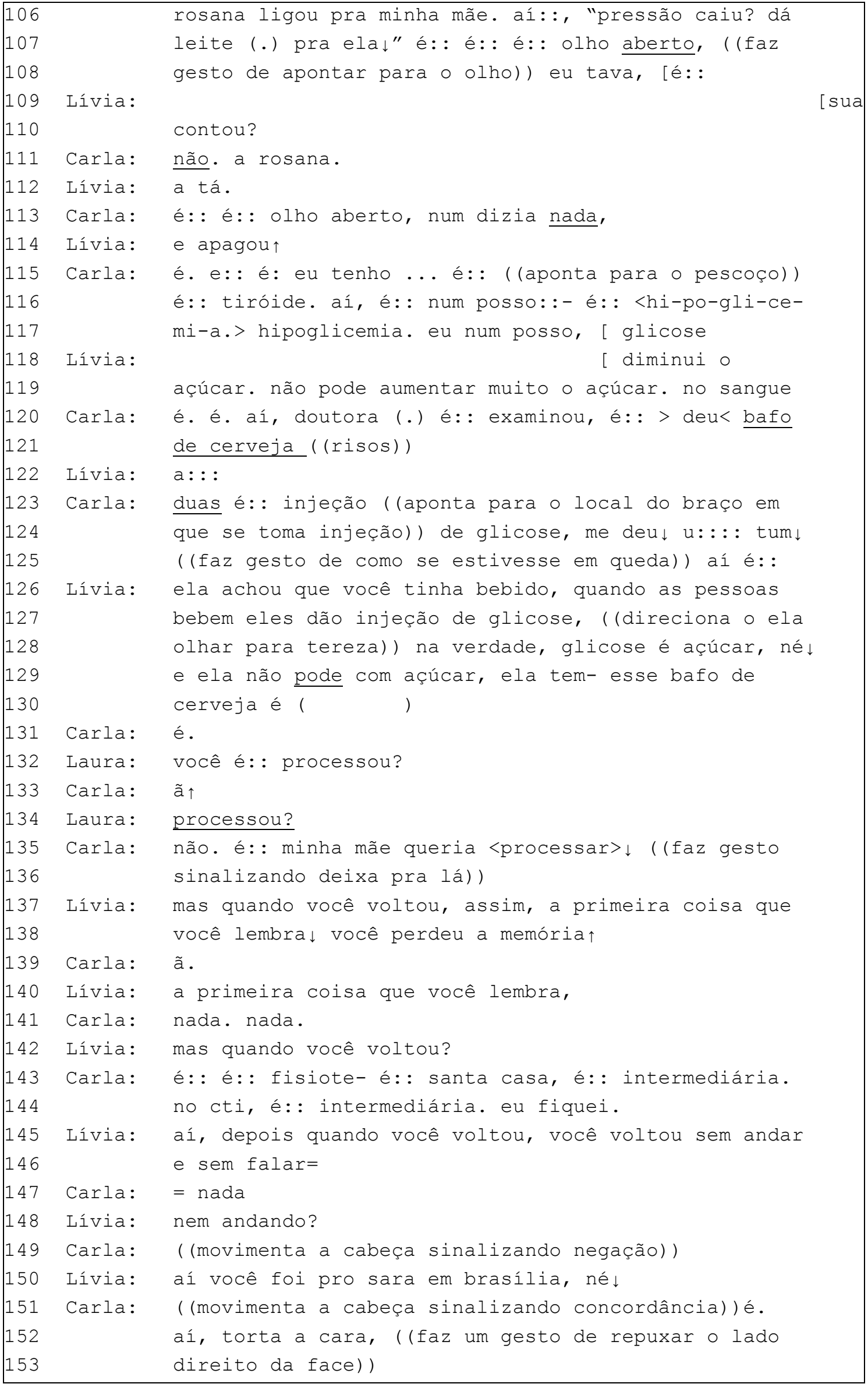




\subsection{COMO OCORRE O TRABALHO INTERACIONA DE ENCAIXE DA NARRATIVA NA ATIVIDADE DISCURSIVA EM CURSO?}

$\mathrm{Na}$ História de Carla, Lívia, mediante o papel por ela assumido e ratificado pelas participantes da interação (moderadora e distribuidora dos pisos conversacionais), aloca Carla como próxima falante, convidando-a a narrar ("e você $\uparrow>$ conta pra gente, a sua histó:rial<<de como você foi>- de como que foi-"), linhas 01-03, numa proposta de encaixe de sua história de AVC na conversa em curso. A ação de Lívia nesse turno atua na conquista de um espaço para Carla narrar sua história, bem como aponta para a relevância da história naquele contexto sequencial (após uma outra narrativa de AVC, a história de Laura) ao demonstrar, nas linhas 3-4, a possibilidade de uma similaridade temática entre as duas histórias que torna a narrativa de Carla relevante e significativa para a interação em curso ("só pra elas verem se foi igual $\downarrow$ ”. É importante destacar que Carla já havia contado sua história anteriormente para Lívia, de modo que o enunciado de Lívia nas linhas 3-4 também pode ser entendido como uma justificativa (de Lívia para Carla) para a solicitação da recontagem.

O convite para narração acima referido ("conta pra gente, a sua histó:ria」"), linhas 01-02, é aceito por Carla, que, dispensando o sumário, constrói a orientação da narrativa ("rosana, minha tia, foi me buscar, é:: no aniversário. é:: eu ... é: : vou é:: ... junto com ela. aí, na casa dela, eu: é:: retrato, eu é: : via é: quinze anos da filha dela."), linhas $05-07$, demonstrando que aceita a proposta de encaixar sua narrativa na atividade discursiva.

Carla constrói uma breve narrativa em apenas um turno (linhas 01-18). Ao expressar por meio de uma onomatopeia - “TU: : : :M $\mathrm{M}_{\downarrow}$ " - e de gestos a sua queda naquela sequência de fatos, ela constrói a resolução da narrativa. Todavia, a colaboração das participantes, que se engajam na coconstrução dessa narrativa, revela-se em ações que buscam a expansão da breve narrativa, ao encorajarem Carla a prosseguir com a narração ("aí você acordou- você desmaiou e acordou como?", linha 27; "e: : torta?", linha 29; "mas AVC é: : stress?", linha 40;), sinalizando, por outro lado, que a narrativa de Carla carece de informações relevantes para sua finalização. As ações das participantes, que se configuram como um convite ao retorno à narração, também podem ser interpretadas como uma recusa da proposta de finalização da narrativa de Carla. Tais ações corroboram o caráter colaborativo dessa construção e a tese que considera que, quando o interlocutor é ratificado como conarrador, ele obtém o direito de intervir na trajetória da narrativa, através de perguntas, comentários entre outras ações (cf. NORRICK, 2007).

Desde a resolução da narrativa (linha 18), que, como vimos, foi seguida de uma solicitação de esclarecimento da parte de Lívia (linha 27), ocorreu um re-engajamento das participantes na conversa, cujo tópico passou a ser o que as participantes consideravam fatores etiológicos de um AVC. No entanto, após alguns turnos de 
conversa, Carla volta a narrar, através de acréscimos de orações narrativas (expansão da ação complicadora) - "é: : aqui:: minha irmã é:: é: : é: : minha irmã, ligou pra minha mãe, é:: "carla desmaiou aqui" $\downarrow$,", linhas 102-103; "é. é: : é: : desmaiou aqui. é:: é:: rosana ligou pra minha mãe. aí::, "pressão

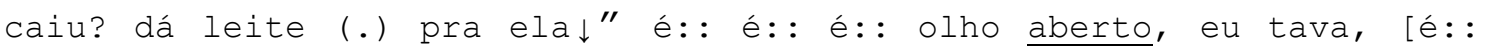
é:: é:: olho aberto, num dizia nada,", linhas 105-113 - rumo à construção do que parece ser uma nova resolução da narrativa, construída com o mesmo recurso da resolução anterior ("duas é:: injeção de glicose, me deu $\downarrow$ u:::: tum $\downarrow$ ", linhas 123-124), numa atitude de encaixe de sua história na conversa em andamento. Podemos entender essa ação de Carla como um reconhecimento de que sua narrativa estava incompleta, conforme sinalizado pelas perguntas das interlocutoras. Após esse momento, ocorreu, novamente, um retorno à conversa, até o momento em que Lívia encaixa, novamente, a história de Carla na conversa, ao solicitar mais uma vez, informações sobre o estado de Carla após o AVC nas linhas 137-138: "mas quando você voltou, assim, a primeira coisa que você lembra $\downarrow$ você perdeu a memória $\uparrow^{\prime \prime}$, que é aceita por Carla no turno seguinte. Essa ação de Lívia conecta a história de Carla ao momento presente da conversa .

O retorno à narração, isto é, o reencaixe da história na conversa, toma o formato de breves relatos deflagrados turno a turno pelas construções (ações) das participantes (realizações de elaborações, solicitações de elaboração, solicitações de clarificação), permeados por trechos de conversas, cujos tópicos apresentam uma relação direta com o que foi previamente narrado. Tal configuração é típica de o que Ochs e Capps (2001) descrevem como narrativas encaixadas (em contraste com narrativas isoladas), pois (i) são contadas em turnos de extensões similares aos turnos que as precedem, (ii) são tematicamente relevantes a um tópico sob discussão ou a uma atividade em andamento, e (iii) seus formatos retórico assumem características do discurso circundante.

\subsection{QUAIS AS AÇÕES REALIZADAS PELAS CONARRADORAS NA CONSTRUÇÃO DA NARRATIVA?}

Conforme podemos observar, as interlocutoras se lançam espontaneamente no curso da narração, colaborando na construção da narrativa de Carla e tomando o turno para:

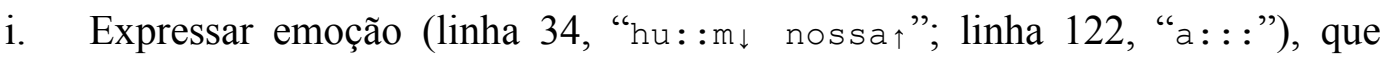
podemos considerar ser um tipo de avaliação, nos termos de Labov, sinalizando o envolvimento das interlocutoras (Laura e Lívia), bem como o incentivo à Carla para prosseguir com sua narrativa, através da demonstração de apreciação da significância da história de Carla.

ii. solicitar elaboração (linha 27, "aí você acordou- você desmaiou e acordou como?"; linhas 109-110, "sua mãe contou?";), demonstrando atenção e interesse na narrativa de Carla, ao mesmo tempo que a auxiliam na ordenação (estruturação) dos eventos por meio de cooperative promptings, colaborando, portanto, com a organização sequencial da narrativa. 
iii. Solicitar clarificação (linha 29, "e:: torta?"; linhas 36-37, "mas quando você voltou $\downarrow$ à consciência, o que você lembra? como você estava"; linha 40, "é:: mas AVC é:: stress?"; linha 114, "e apagou个"; linhas 137-138, "mas quando você voltou, assim, a primeira coisa que você lembra $\downarrow$ você perdeu a memória.", reconhecendo a proposta de finalização da história, e, por outro lado, auxiliando Carla na construção do desfecho da narrativa e da coda (i.e. retorno para o aqui e agora da interação).

iv. realizar elaboração (linha 104, "a é:: o seu caso. [ continua a contar,"; linhas 118-119, "diminui o açúcar. não pode aumentar muito o açúcar. no sangue"; linhas 126-130, "ela achou que você tinha bebido, quando as pessoas bebem eles dão injeção de glicose, na verdade, glicose é açúcar, né $\downarrow$ ”, colaborando na inteligibilidade da narrativa de Carla.

v. avaliar (linha 19, "igual ao dela."; linha 21, "foi súbito."; linha 23, "foi rápido."; linha 25, "foi na hora."), marcando a diferença entre os episódios de AVC relatados por Laura (uma longa trajetória de sofrimento, que gerou uma extensa narrativa) e por Carla (um episódio que durou apenas alguns minutos, que gerou uma narrativa breve). Observa-se que essas ações avaliativas de Lívia ao final da narração se justificam pelo modo como ela escolheu fazer o convite à Carla para contar sua história: motivação à narração pela busca da semelhança com a história de Laura ("só para elas verem se foi igual").

Podemos considerar que o que chamou mais atenção para o caráter interacional da narrativa de Carla foram as diversas intervenções das interlocutoras na determinação da trajetória, da estrutura e do ponto da história, através das ações elucidadas acima, de modo que o conteúdo e o formato foram fortemente influenciado pelos inputs das interlocutoras, em atitudes de co-narração. A participação de Lívia destaca-se pelo que Ochs, Smith e Taylor (1988) chamam de envolvimento/ comprometimento (commitment), que se configura em ações por meio das quais o interlocutor exibe persistência, realiza conexões e esboça inferências.

\subsection{COMO A LINEARIDADE, ASSIM COMO A QUEBRA DA LINEARIDADE, EMERGEM NA NARRATIVA?}

Tendo como parâmetro os postulados de Ochs e Capps (2001) acerca da quebra da linearidade, analisaremos a história de AVC de Carla, entendendo que aqui ocorrem suspensões ou desvios do fluxo narrativo quando:

i. a sequência temporal é interrompida: Carla, nas linhas 102-103, expande sua narrativa com acréscimo de algumas ações complicadoras ("é: : aqui:: minha irmã é:: é:: é:: minha irmã, ligou pra minha mãe, é::

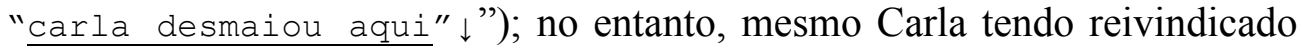
atenção para si ao proferir "aqui : :", a ação de Lívia no turno seguinte, linha 104 - "a é: : o seu caso. continua a contar," - sinaliza que ela (Lívia) não esperava um retorno à narração naquele momento, ao mesmo 
tempo que acaba provocando uma breve suspensão da linearidade da narração. Novamente, nas linhas 109-110, Lívia suspende a narração para realizar uma inferência ("sua mãe contou?"). Quando Carla retoma a narração ("é: : é: : olho aberto, num dizia nada,"), na linha 113, ela é novamente interrompida por Lívia, que realiza uma pergunta de esclarecimento ("e apagou $\uparrow$ "). Após esse turno, ocorre um desvio da narração. Quando Carla retorna a narrar, na linha 120, dando prosseguimento à ação complicadora ("é. é. aí, doutora (.)é:: examinou, é: : > deu< bafo de cerveja"; "duas é: : injeção duas é: : injeção aí é: :"), logo após fazer uso de uma juntura temporal, sinalizando que seu relato continuaria ("aí é: :"), linha125, é interrompida por Lívia, nas linhas 126-127, que realiza uma clarificação do relato de Carla ("ela achou que você tinha bebido, quando as pessoas bebem eles dão injeção de glicose,").

ii. o enredo carece de coerência: a partir da linha 137 até o final da narrativa, as ações de Lívia sinalizam que ela considerou que a história de Carla carecia de elaboração e de mais informações. Desde a linha 137, Lívia apresenta solicitação de mais informações ("você lembra $\downarrow$ você perdeu a memória.", linhas 137-138; "a primeira coisa que você lembra,", linha 140; "mas quando você voltou?", linha 142), mas Carla prossegue com um relato lacônico, de fala hesitante ("é: : é: : fisiote- é: : santa casa, é:: intermediária. no CTI, é:: intermediária. eu fiquei.", linhas 143-144) que não colabora com a proposta de elaboração e finalização da narrativa de Lívia, além de suspender a linearidade da narrativa, a qual Lívia estava tentando recuperar. Tal linearidade só foi recuperada com as elaborações de Lívia nas linhas 145-146 (“aí, depois quando você voltou, você voltou sem andar e sem falar"), 148 (“nem andando?") e 150 (“aí você foi pro Sara em Brasília, né ’”), que foram ratificada por Carla nos turnos seguintes a cada elaboração.

iii. o narrador sai do mundo da história e volta ao mundo real, de modo que suas construções com verbos no passado cedem lugar a construções com verbos no presente do indicativo: no curso da construção da versão expandida da história, Carla interrompe a narração para fazer um comentário nas linhas 115-117 ("é. e: : é: eu tenho ... é: : é:: tiróide. aí, é:: num posso::- é:: <hi-po-gli-ce- mi-a.> hipoglicemia. eu num posso, [ glicose"). Tal movimento, embora suspenda a linearidade de sua narrativa, permite que ela forneça informações relevantes para o entendimento da mesma, logo, para a manutenção da intersubjetividade, além de exibir um aspecto avaliativo.

iv. ocorre repetição de enunciados e temas: as repetições e as correções encaixadas (cf. JEFFERSON, 1987) realizadas por Carla também suspendem (muito brevemente) a linearidade da narração, como podemos observar nas linhas 08-09 (“aí é: choveu. é:: tava chovendol”), 09-10 (“aí é: : é:: latinha de cerveja, eu tava tomando, uma latinha de 


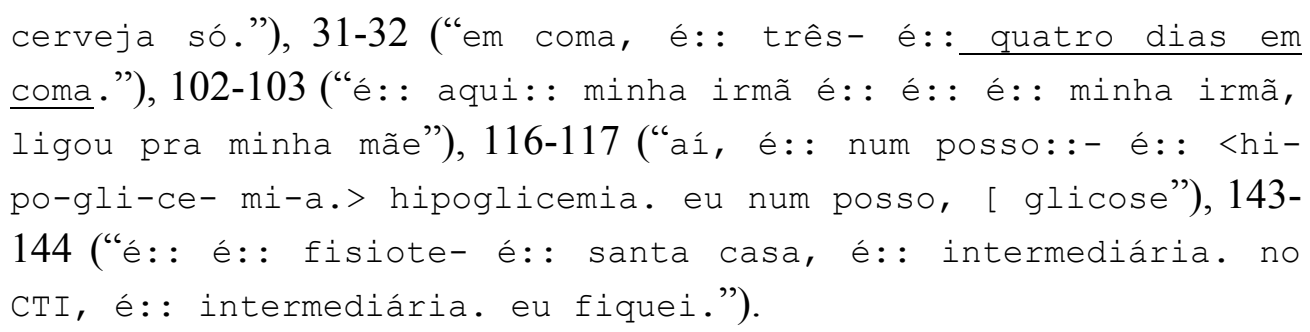

\subsection{QUAIS RECURSOS SÃO UTILIZADOS PELA NARRADORA} PARA CONSTRUÇÃO DA HISTORIABILIDADE DA NARRATIVA?

Carla, nas linhas 05-10, inicia sua narrativa com uma longa orientação ("rosana, minha tia, foi me buscar, é:: no aniversário. é:: eu ... é: : vou é: : ... junto com ela. aí, na casa dela, eu:: é:: retrato, eu é: : via é: quinze anos da filha dela. aí é: choveu. é: : tava chovendo $\downarrow$ aí é: é: : latinha de cerveja, eu tava tomando, uma latinha de cerveja só."), que monta o cenário da breve cena do episódio de AVC. Nesse trecho, Carla realiza cinco momentos de avaliação por meio de dispositivos internos, quando atribui ênfase à expressão "na casa dela" (intensificador do tipo fonologia expressiva) e ao repetir a expressão "latinha de cerveja" (intensificador do tipo repetição) e acrescentar o quantificador "uma" (intensificador), bem como ao fazer uso de correlativos do tipo

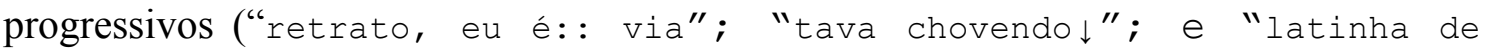
cerveja, eu tava tomando"). Além disso, ao proferir "uma latinha de cerveja só.", Carla faz um gesto com a mão esquerda de aproximação dos dedos indicador e polegar, sinalizando pouca quantidade, o que confere maior força avaliativa a essa expressão, visto que o gesto é um outro tipo de intensificador. Observamos, então, quatro inserções de avaliações na orientação, que realçam os seguintes fatos: o AVC aconteceu na casa da tia de Carla; e Carla, no momento do AVC, estava ingerindo apenas uma latinha de cerveja. Esta última avaliação nos sugere, por um lado, que Carla busca na situação que antecede o AVC uma razão para o acontecido, mas não encontra; e por outro, que a ação de ingerir uma latinha de cerveja tem alguma relação com o ponto da história, se consideramos que as avaliações apontam para o ponto da narrativa (cf. LABOV, 1972; BASTOS, 2005).

Após orientar os interlocutores de sua história acerca do local do evento e das pessoas que estavam ali presentes, Carla, nas linhas 13-18, utiliza a conjunção "aí" e dá início à ação complicadora, à narração, propriamente dita ("aí é: : quer que eu é: : é::- a roupa dela tava no é:: varal. é:: é:: "rosana $\uparrow$ quer que eu

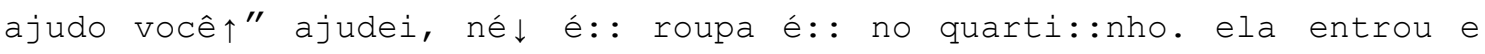

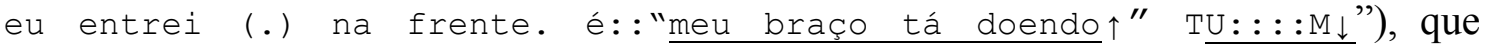
ocupou apenas cinco linhas, uma vez que podemos considerar que ao proferir “TU: : : :M $\downarrow$ ", juntamente com um gesto que sinaliza queda, Carla está apresentando a última ação da sequência da complicação de sua narrativa, logo, a resolução. Nesse breve trecho de relato, podemos verificar a presença de duas avaliações realizadas por meio de fonologia expressiva em "meu braço tá doendo" e "TU:::: M", e de dois encaixes de avaliações (cf. LABOV, 1972; p.), quando Carla faz uso do discurso 


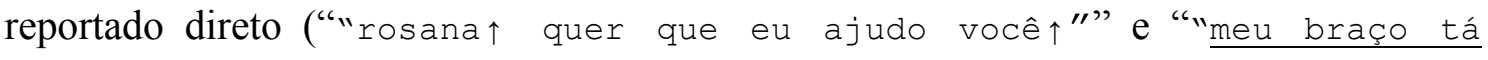
doendo $\uparrow "$ "'). Cabe considerar que nesses momentos, um pequeno drama foi criado, o que, de certo modo, confere historiabilidade à narrativa de Carla, nas palavras de Goffman (1974), ao pequeno show de Carla.

Lívia, na linha 27, apresenta o que podemos tratar como uma proposta de continuação para a narrativa de Carla ("aí você acordou- você desmaiou e acordou como?"), que consiste em uma solicitação de detalhamento, ação típica de narrativas conversacionais (cf. OCHS e CAPPS, 2001), que é respondida no turno seguinte, na linha 28, por Carla ("no hospital"). No entanto, a resposta de Carla não foi suficiente para Laura, outra interlocutora, que, no turno seguinte, na linha 29, em uma demonstração de atenção e interesse pela história de Carla, realiza uma nova solicitação de detalhamento ("e: : torta?"), o que nos leva a assumir que a narrativa de Carla, mesmo sendo breve, conseguiu envolver o ouvinte. Laura, ao menos, mostrouse envolvida com o pequeno drama de Carla, o que pode ser novamente verificado pelo seu enunciado da linha 34, por meio do qual ela expressa emoção (“hu : : m $\downarrow$ nossa $\uparrow ")$, logo após Carla relatar ter ficado quatro dias em coma, acrescentando detalhas à sua narrativa, conforme solicitado pelas interlocutoras interessadas em sua história.

$\mathrm{O}$ interesse alcançado pela narrativa de Carla da parte das interlocutoras, por um lado, aponta para sua historiabilidade, e por outro, justifica o fato de após o longo período da conversa desencadeada por sua narrativa, que sucedeu a linha 34, ela ter dado continuidade à narração, que, até então, possivelmente tinha sido interpretada como finalizada pelas interlocutoras. Nas linhas 102-103, Carla reivindica a atenção das interlocutoras ("é: : aqui: :") e prossegue com a narração, acrescentando detalhes que não foram antes apresentados ("minha irmã é:: é: : é:: minha irmã, ligou pra minha mãe, é:: "carla desmaiou aqui" $\downarrow ")$. Esse retorno à narração é ratificado por Lívia, que, no turno seguinte, linha 104, na posição de pesquisadora/ moderadora, profere uma autorização para Carla prosseguir com o relato de sua história ("a é: : o seu caso. [ continua a contar,"). Carla, então, continua sua narrativa, que se estende da linha 105 à 124. Nesse trecho, Carla foi interrompida diversas vezes por Lívia, cujas ações, como vimos, além de sinalizar atenção e acompanhamento do relato, buscavam sustentar a linearidade e a intersubjetividade da narrativa.

Independentemente dessa fragmentação da sua história, o que é esperado acontecer em narrativas contadas em meio a conversas, Carla sustentou a historiabilidade de sua narrativa por meio da manutenção do seu caráter dramático, alcançado pelo uso dos mesmos recursos dos quais se valeu na primeira parte da história. São eles: encaixe de avaliação, na forma de discurso reportado direto ("'carla

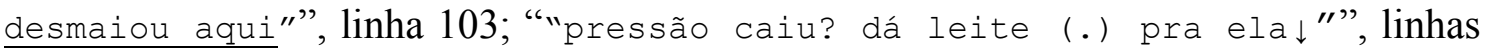
106-107); avaliação por suspensão da ação complicadora ("olho aberto", linha 107); fonologia expressiva ("carla desmaiou aqui"," linha 103; "aberto", linha 107; "nada", linha 113; "bafo de cerveja", linhas 120-121; "duas é: : injeção", linha 123); quantificador ("nada", linha 113); correlativos do tipo progressivos ( "num dizia nada”, linha 113); e gesto, linha 125. 
Com a ênfase atribuída às expressões "bafo de cerveja", linhas 120-121, e "duas é: : injeção", linha 123, podemos sustentar que o ponto da narrativa de Carla vinha sendo apontado por dispositivos internos de avaliação desde a primeira parte da história, quando Carla, por meio desses dispositivos, destacou que havia ingerido apenas uma latinha de cerveja. Logo, um olhar para essa ênfase nos permite alcançar um possível ponto da narrativa: o equívoco de diagnóstico. Segundo o relato de Carla, ela não havia ingerido bebida alcoólica o suficiente para entrar em coma alcoólico, conforme diagnóstico médico, o que não justificaria o procedimento clínico de aplicação de injeção de glicose.

Novamente, após essa segunda parte da história, que foi finalizada do mesmo modo que a primeira parte, isto é, com o desmaio de Carla, parafraseado pela onomatopeia "tum" e por um gesto de queda, as interlocutoras se engajaram em uma conversa sobre o relato de Carla. $\mathrm{O}$ fato de a narrativa de Carla ter desencadeado uma conversa que estendeu o tópico da narração já nos diz que sua narrativa é historiável, pois as interlocutoras, por meio de suas ações, demonstraram interesse pelo evento narrado, além de Laura ter demonstrado indignação com o equívoco da médica, na linha 132 ("você é:: processou?"), que, por sua vez, estruturou a historiabilidade da narrativa de Carla desde a primeira parte.

\subsection{COMO A NARRADORA AFÁSICA CONSTRÓI A SI E AO OUTRO (EM TERMOS DE POSTURAS MORAIS) E AS REALIDADES QUE A CERCAM, DIANTE (ATRAVÉS) DO EPISÓDIO DE AVC POR ELA NARRADO?}

Nas linhas 09-10 de sua narrativa ("latinha de cerveja eu tava tomando. uma latinha de cerveja só."), Carla confere ênfase à quantidade de cerveja por ela ingerida ("uma"; "só"), o que nos permite inferir que ela julga, informada pelos valores de sua cultura, que não se deve ingerir grande quantidade de bebida alcoólica, e que ela, uma vez que só ingeriu uma latinha de cerveja, está assumindo uma postura moralmente correta. Assim sendo, a causa do AVC por ela sofrido naquele momento, com base em suas construções discursivas, não poderia ter sido por ela (Carla) desencadeada, já que seu comportamento no momento do acometimento não condizia com o que ela considera ser um fator etiológico de AVCs - o consumo exagerado de bebidas alcoólicas. Nesse sentido, neste trecho inicial da narrativa, Carla se exime de responsabilidade em relação ao episódio de AVC, que, segundo seu relato, acometeu-a repentina e inexplicavelmente, como pode ser observado nas linhas 13-18 ("a roupa

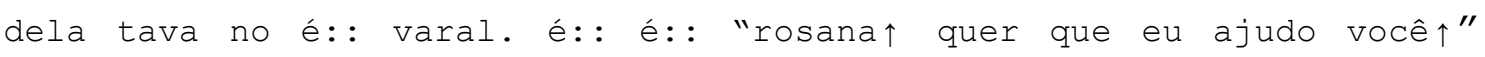
ajudei, né $\downarrow$ é: roupa é: no quarti::nho. ela entrou e eu entrei (.)

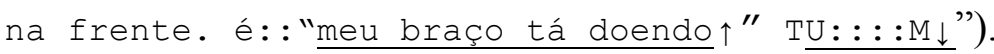

Após algumas sequências de conversa desencadeadas por esse trecho da história de Carla, ela retoma a narração a partir do ponto onde havia parado. Com base no contexto sequencial de sua narrativa, podemos interpretar que Carla, nas linhas 120-124, relata o que aconteceu ao chegar ao hospital: “aí, doutora (.)é: : examinou, é: :

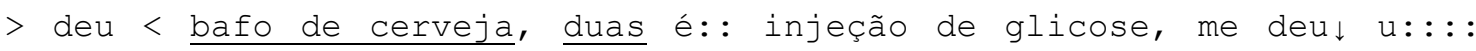


tum $\downarrow$. É assim que a narradora constrói como negligência o diagnóstico recebido e como inadequado o tratamento ministrado (aplicação de insulina quando o diagnóstico exato seria $\mathrm{AVC}$, e não coma alcoólico). Carla atribuiu ênfase a elementos que são índices do equívoco de diagnóstico - "bafo de cerveja" - e do equívoco de tratamento - "duas é: : injeção de glicose".

Embora, segundo seu relato, o equívoco de diagnóstico tenha ocorrido, Carla exibe uma atitude passiva e conformista perante o acontecido. Quando Laura pergunta a ela se ela processou a médica, ela responde "não. é: : minha mãe queria <processar> $"$ " (linha 135) e faz um gesto que, culturalmente, consiste em uma paráfrase não verbal da expressão "deixa pra lá”. A aceitação de Carla está presente no curso de toda a interação, o que nos sugere que tal postura é para ela positiva. Em sua breve narrativa, ela não posiciona como injustiçada, sofredora, azarada, o que é esperado em narrativas de doença (cf. OLIVEIRA e BASTOS, 2012).

Por outro lado, tal atitude de Carla não torna sua história menos envolvente, uma vez que ela, como vimos anteriormente, ao fazer uso de ênfase (linhas 07, 10, 18, 32, $103,107,120-121,123,152$ ), gestos (linhas 10-12, 17-18, 31-32, 107-108, 115, 123 $124,152-153)$ e discursos reportados $(14,16,103,106-107)$, constrói sua história de AVC como um verdadeiro drama, ao mesmo tempo em que se constrói como protagonista conformada desse drama.

Como algumas vezes aqui reiterado, narrativas pessoais muitas vezes remetem a incidentes da vida em que protagonistas violam expectativas sociais. No caso de narrativas de AVC, a expectativa não é que pessoas acometidas por essa patologia se posicionem como protagonistas conformados; por isso, em sua narrativa, a atitude de Carla nos chama a atenção. Embora viole expectativas, ao longo da narração, Carla se ateve em projetar uma imagem positiva de si, não se ocupando da projeção de uma imagem negativa do outro.

\section{DISCUSSÃO DA ANÁLISE}

Iniciamos por destacar que a análise da dimensão narração nos possibilitou captar as particularidades do caráter colaborativo da narrativa. Essa dimensão trouxe à luz as ações colaborativas das interlocutoras, realçando como tais ações eram indispensáveis tanto à construção de narrativas coerentes e inteligíveis, como à própria intersubjetividade da interação/ narração, tendo-se em conta que as narradoras primárias apresentam um comprometimento da linguagem que impõe limitações às suas produções verbais.

Goodwin (1995) mostra que, em interações com afásicos, quando os interlocutores coordenam suas participações atentando para a sequência dos eventos interacionais, é possível, de modo conjunto, superar as limitações impostas, até mesmo, por vocabulários repetitivos e severamente reduzidos dos afásicos. Neste estudo foi possível observar a cooperação das interlocutoras por meio de diversas ações; algumas 
dessas ações apontavam para as particularidades das narrativas analisadas (i.e. relatos de pessoas com afasia), uma vez que, sequencialmente, sucederam turnos em que o comprometimento da linguagem da narradora interveio desfavoravelmente, em relação aos quais as ações das interlocutoras foram as seguintes: finalização de enunciados, solicitação de clarificação, clarificação de caráter explicativo, verificação de entendimento, solicitação de elaboração e elaboração.

Voltando a atenção para outra dimensão, a historiabilidade, o que se faz interessante iluminar é o fato de que, não obstante o comprometimento linguístico apresentado pela participante deste estudo, ela, enquanto narradora primária ativamente engajada na construção de seu relato, de modo bastante habilidoso, valeu-se de uma gama de recursos avaliativos no desenho da historiabilidade de sua narrativa. $\mathrm{O}$ uso que a participante fez de mecanismos internos e externos de avaliação fomentou o caráter historiável de sua narrativa, não obstante tal caráter já ter sido imposto pelo tópico das histórias (AVC, um acontecimento extraordinário), bem como pelas suas significâncias para o contexto de suas ocorrências (interações entre pessoas que sofreram AVC), o que corrobora a tese de que a historiabilidade não se limita àquilo que, com base em nosso conhecimento de mundo, reconhecemos como extraordinário, podendo estar parcialmente relacionada à organização do narrador, ou seja, às habilidades retóricas por ele utilizadas (cf. OLIVEIRA e BASTOS, 2002).

Quando investigamos a dimensão encaixe, observamos, novamente, a habilidade de pessoas com afasia ao lidar com o turno a turno das construções narrativas. Novamente nessa dimensão é possível verificar a colaboração do outro por meio de ações que entrecortam a narração, coconstruindo as narrativas. Levando-se em conta que o encaixe da narração em uma atividade discursiva em andamento é uma ação negociada (cf. SACKS, [1968] 1992; GARCEZ, 2001; NORRICK, 2007), na análise aqui empreendida, identificamos que tal negociação foi iniciada pela pesquisadora/ moderadora, na forma de convites à narração.

As ações do outro no curso da narração, tão destacadas na análise, constituíram substrato para a análise de uma outra dimensão narrativa - a linearidade. Por meio das ações das conarradoras, houve ora suspensão ora restauração da linearidade. O fluxo da narração do episódio de AVC foi interrompido pelas conarradoras, ao realizarem ações que suspendiam a linearidade por interromper a sequência temporal. Porém, tal fluxo também foi restaurado por meio de ações que restauravam a linearidade. Em suma, as conarradoras assim como a narradora primária atuam conjuntamente na estruturação da linearidade da história analisada.

No que diz respeito à postura moral da narradora ao longo da narrativa, observamos que esta se configurou como determinada e constante. Ao longo de toda a narração, Carla se apresentou sob uma luz favorável, ao mostrar aceitação e compreensão perante um possível equívoco de diagnóstico, assumindo uma postura moral positiva. 
A partir dos resultados aqui apresentados e discutidos, defendemos que a fala afásica, com suas limitações linguísticas, impostas por um comprometimento da linguagem decorrente de lesão cerebral adquirida, não impossibilitou a participante deste estudo de atuar como narradora e se engajar ativamente em construções discursivas (de sentido, princípios, valores, posturas, identidades etc.) no curso da narração, e que a colaboração do outro enquanto conarrador foi extremamente significativa para as construções alcançadas, para o sucesso da comunicação. Nesse sentido, atribuir coautoria à audiência consiste em reconhecer a necessidade de uma parceria para sustentação de uma interação (DURANTI, 1986). A narradora, de modo habilidoso, contou sua história em conjunto com o outro, de um modo retoricamente efetivo, encaixando sua narrativa na atividade discursiva circundante, com início, meio e fim coerentes e progressivos e uma postura moral consistente. Ademais, no curso da narração, a participante demonstrou conhecimento das normas sociais de uso da linguagem no contexto interacional em questão e de princípios e valores culturais que se impuseram às construções discursivas, guiando-as e estruturando-as.

Enfim, foi possível observar que pessoas com afasia se encontram um espaço para narrar e interlocutores colaboradores, podem se mostrar extremamente habilidosas na escolha de novos arranjos para construção de sentidos, adaptando suas limitações para lidar com as demandas da interação em curso.

\section{REFERÊNCIAS}

BASTOS, L. C. Diante do sofrimento do outro - narrativas de profissionais de saúde em reuniões de trabalho. Calidoscópio, v. 6, n. 2, p. 76-85, 2008.

Contando estórias em contextos espontâneos e institucionais: uma introdução ao estudo da narrativa. Calidoscópio, v. 3, n. 2, p. 74-87, 2005.

Narrativa e vida cotidiana. SCRIPTA, v.14, n. 7, p.118-127, 2004.

Histórias de mulheres e homens: narrativa, sexo e construção de identidade. The Especialist, v.

20, n.1, p. 17-29, 1999.

BRUNER, J. Acts of meaning. Cambridge: Harvard University Press, 1990. 208p.

COUDRY, M. I. H. Neurolinguística discursiva: afasia como tradução. Estudos da Linguagem, v. 6, n. 2, p. 07-36, 2008.

GOLDSTEIN, K. Language and language disturbances. New York: Grune and Stratton, 1948. 374p.

. The organism: a holistic approach to biology derived from pathological data in man. New York: Zone Books, 1939 422p.

GOODWIN, C. Audience diversity, participation and interpretation. Text, v. 6, n. 3, p. 283-316, 1986.

Co-constructing meaning in conversations with an aphasic man. Research on Language and Social Interaction, v. 28, p. 233-60, 1995.

HEESCHEN, C.; SCHEGLOFF, E. A. Aphasic agrammatism as interactional artifact and achievement. In: GOODWIN, C. (Org.). Conversation and brain damage. New York: Oxford University Press, 2003. p. 231-282.

JACKSON, J. H. Selected Writings of John Hughlings Jackson. In: TAYLOR, J. (Org.). London: Hodder and Staughton, 1931. 
LABOV, W. The transformation of experience in narrative syntax. In: inner city. Philadelphia, University of Philadelphia Press, 1972, p. 354-396.

(Org.). Language in the

LABOV, W.; WALETZKY, J. Narrative Analysis: oral versions of personal experience. In: HELM, J. (Org.). Essays on the verbal and visual arts. Seattle, University of Washington Press, 1967. p. 12-44.

MORGAN, D. L. Focus group interviewing. In: GUBRIUM, J.; HOLSTEIN, J. (Orgs.). Handbook of Interview Research: Context and Method. London, Sage, 2002. p. 141-160.

MISHLER, Elliot. Storylines. Craftartists' narratives of identity. Cambridge: Harvard Univeristy Press, 1999. 180p.

NORRICK, N. R. Narrative contexts. In: (Org.). Conversational narrative: storytelling in everyday talk. Philadelphia: John Benjamins Publishing Company, 2000. p. 105-134.

OCHS, E.; CAPPS, L. Living Narrative: Creating Lives in Everyday Storytelling. Harvard: Harvard University Press, 2001. 352p.

OCHS, E.; SMITH, R.; TAYLOR, C. Detective stories at dinnertime: problem-solving through conarration. In: AMERICAN ETHNOLOGICAL SOCIETY ANNUAL MEETINGS, SYMPOSIUM ON NARRATIVE RESOURCES FOR THE CREATION OF ORDER AND DISORDER, 1988, California, Texto de Apresentação Oral, California: University of Southern California, 1988. p. 01-35.

OLIVEIRA, L. M.; BASTOS, L. C. Uma história de AVC: a construção do sofrimento por uma pessoa com afasia. Veredas - Revista de Estudos Linguísticos, v.15, n.1, p. 120-135, 2011.

OLIVEIRA, M.C.L.; BASTOS, L.C. A experiência de imigração e a construção situada de identidades. Veredas - Revista de Estudos Linguísticos, v.11, n. 2, p. 31-48, 2002.

RIESSMAN, C. K. Narrative analysis. Newbury Park: Sage, 1993. 79p.

. Narrative Methods for the Human Sciences. Sage Publication, 2008. 250p.

WILKINSON, R. et al. Adapting to conversation as a language-impaired speaker: Changes in aphasic turn construction over time. Comunication \& Medicine: An Interdisciplinay Journal of Healthcare, Ethics \& Society. v. 4, n. 1, p. 79-98, 2007.

\section{ANEXO A: CONVENÇÕES DE TRANSCRIÇÃO}

\begin{tabular}{ll}
\hline [colchetes] & fala sobreposta \\
$()$. & micropausa \\
$=$ & contiguidade entre a fala de um mesmo falante ou de dois falantes distintos \\
$?$ & descida de entonação \\
, & subida de entonação \\
$:$ & entonação contínua \\
- & alongamento de som \\
Sublinhado & Autointerrupção \\
MAIÙSCULA & ênfase acentuada \\
$((\quad))$ & comentários do analista \\
(palavras) & transcrição duvidosa \\
$($ ) & transcrição impossível \\
a. & pausa não medida \\
palavra” & fala reportada, reconstrução de um diálogo
\end{tabular}

OLIVEIRA, Lívia Miranda de; BASTOS, Liliana Cabral. Narrando em colaboração: as construções discursivas de uma pessoa com afasia. Linguagem em (Dis)curso - LemD, Tubarão, SC, v. 14, n. 2, p. 247-267, maio/ago. 2014. 
Recebido em: 28/07/13. Aprovado em: 05/08/14.

Title: Narrating in collaboration: Discursive constructions by an aphasic person

Authors: Lívia Miranda de Oliveira; Liliana Cabral Bastos

Abstract: This article uses the theoretical framework of Narrative Analysis (RIESSMAN, 1993; 2008; BASTOS, 2005, 2008), and brings structural (LABOV; WALETZKY, 1967; $L A B O V$, 1972) and interactional (NORRICK, 2000; GOODWIN, 1986) perspectives of narrative analysis together in order to investigate the collaborative construction of narrative and the discursive construction of a person with aphasia. Through the analysis of narrative dimensions (OCHS; CAPPS, 2001), we observed the high involvement of cotellers in the narrative construction, in the placement of the narrative in the discursive activity and in the construction of linearity. Furthermore, the aphasic teller has performed tactical rhetorical choices (of evaluation devices) to construct the narrative tellability and a positive, determined and constant moral stance.

Keywords: Narrative. Interaction. Aphasia.

Título: Narrando en colaboración: construcciones discursivas de una persona con afasia Autores: Lívia Miranda de Oliveira; Liliana Cabral Bastos

Resumen: Insertándose en el cuadro teórico y metodológico del Análisis de Narrativa (RIESSMAN, 1993; 2008; BASTOS, 2005, 2008), este estudio se vale de estudios canónicos (LABOV; WALETZKY, 1967; LABOV, 1972) e de interacción (NORRICK, 2000; GOODWIN, 1986) para investigar la construcción colaborativa de la narrativa y las construcciones discursivas de una persona con afasia. Eligiendo la propuesta das dimensiones de la narrativa de Ochs y Capps (2001) como categoría analitica, fue posible observar un alto involucramiento de co-narradoras en la construcción de la narrativa, sobretodo en su encaje en la actividad discursiva, asi como la emergencia de la linealidad, también como un emprendimiento que cuenta con la cooperación de co-narradoras. Además, fueron destacadas las habilidosas elecciones retóricas de la narradora (de recursos evaluativos) en la construcción de la alta característica histórica de su narrativa, y su alineamiento con una postura moral positiva, determinada y constante.

Palabras-clave: Narrativa. Interacción. Afasia. 